\title{
The associations of age, lifestyle factors and chronic disease with testosterone in men: the Tromso Study
}

\author{
Johan Svartberg ${ }^{1}$, Monica Midtby ${ }^{3}$, Kaare H Bønaa ${ }^{3,4}$, Johan Sundsfjord ${ }^{2}$, Ragnar M Joakimsen ${ }^{1,3}$ and Rolf Jorde ${ }^{1}$ \\ Departments of ${ }^{1}$ Medicine and ${ }^{2}$ Clinical Chemistry, University Hospital of North Norway, N-9038, Tromso, ${ }^{3}$ Institute of Community Medicine, \\ University of Tromsø, N-9037, Tromsø and ${ }^{4}$ Department of Cardiology, St Olav University Hospital, N-7006, Trondheim, Norway
}

(Correspondence should be addressed to Johan Svartberg; Email: johan.svartberg@unn.no)

\begin{abstract}
Objective: To study whether lifestyle factors and/or chronic disease are associated with the age-related decline of total and free testosterone in men, or if these factors might be associated with the variation of total and free testosterone but not with their age-related decline.

Design: A population-based, cross-sectional study was used.

Methods: Total testosterone and sex hormone binding globulin (SHBG) levels were analyzed and free testosterone levels were calculated in 1563 men participating in the Tromsø study in 1994/1995. Anthropometric characteristics were also measured and two standardized questionnaires completed, including lifestyle factors and medical history. The data were analyzed with multiple linear regression analysis of covariance, and logistic regression.

Results: Total and free testosterone were inversely associated $(P=0.001$ and $P<0.001)$, while SHBG was positively associated $(P<0.001)$ with age. Body mass index $(\mathrm{BMI})$ was inversely associated with total $(P<0.001)$ and free $(P=0.016)$ testosterone and SHBG $(P<0.001)$. Both total and free testosterone were positively associated with tobacco consumption $(P<0.001$ and $P=0.004)$ and total testosterone was positively associated with coffee consumption $(P<0.001)$. SHBG was positively associated with smoking $(P=0.004)$ and coffee consumption $(P<0.001)$. Men who reported having had a stroke or having a cancer diagnosis had lower levels of total testosterone $(P<0.001$ and $P<0.01)$ and free testosterone $(P<0.01)$.

Conclusions: BMI and smoking are independent contributors to the variation of total and free testosterone and SHBG levels, and coffee consumption to the variation of total testosterone and SHBG. Thus, lifestyle factors can have a direct effect on circulating levels of free endogenous sex hormones and to total levels due to the effect on SHBG levels.
\end{abstract}

European Journal of Endocrinology 149 145-152

\section{Introduction}

Several small and large cross-sectional studies have found testosterone levels to decrease with age $(1,2)$, while a few studies did not $(1,3)$. Two longitudinal studies have reported a gradual but progressive decrease in serum testosterone concentration with age; the decline in free testosterone levels being greater than that in total testosterone levels $(4,5)$. Most of the studies of age-related variations in testosterone levels included healthy older men, and it is possible that men with chronic diseases might have even lower testosterone levels. A variety of diseases are linked to sex hormones in men (6-9) and, especially cardiovascular disease, are associated with age, body mass index (BMI) and lifestyle factors such as smoking. Associations have been reported between sex hormones and obesity, smoking, alcohol consumption and exercise, but the results have been inconsistent (10-13).
In this population-based study we investigate whether lifestyle factors are associated with sex hormones, whether they are associated with the decline of total and free testosterone with age, or whether lifestyle factors might be associated with variation of total and free testosterone but not with the age-related decline. We also investigate factors predicting lower levels of total and free testosterone, as well as how chronic disease affects the variation of total and free testosterone.

\section{Methods}

\section{Study population}

The Tromsø Study is a population-based health survey focusing primarily on cardiovascular diseases (14). In the fourth survey, which took place from 1994 to 1995, all men and women aged 25 years or older 
were invited and 80\% (27159 individuals) attended. All participants aged 55-74 years plus random $5 \%$ samples of subjects in the other age groups, and a group of 308 men aged 40-54 years (selected on the basis of high total cholesterol and/or low high-density lipoprotein (HDL) cholesterol) were invited to a second visit for a more extensive examination. A total of 6891 subjects (3393 men) attended the second visit, representing $79 \%$ of the eligible population. Serum samples were drawn for the future analyses of sex hormones in a sub-sample of 1605 men who had been selected randomly by computer for echocardiography. Thus sex hormone analyses were performed for 1605 men of whom 1565 men (including 166 men from the group with high cholesterol) had sufficient serum for all hormone data. Two men using androgen therapy were excluded, leaving 1563 men for these analyses.

\section{Questionnaires}

All participants completed a standardized questionnaire that included the number of cigarettes smoked per day, hours of easy and vigorous physical activity per week, cups of coffee drunk per day, and number of glasses of beer, wine and hard liquor drunk per 2 weeks. From this questionnaire a physical activity score was made by adding together the hours of easy and vigorous physical activity (giving the hours with vigorous activity double weight). An alcohol intake score of beer, wine and hard liquor, assuming an equal amount of alcohol in one glass of each type, was also created.

A second questionnaire on medical history and past and present medication was completed at home and returned by post.

\section{Measurements}

Height and weight were measured with participants wearing light clothing without shoes, and BMI was calculated as weight in kilograms divided by the square of the height in meters $\left(\mathrm{kg} / \mathrm{m}^{2}\right)$.

Blood was drawn by venipuncture non-fasting between 0800 and $1600 \mathrm{~h}$. Serum samples were stored at $-70^{\circ} \mathrm{C}$, until they were first thawed for analysis of sex hormones in 2001, after an average of 6.5 years.

Determination of total testosterone and sex hormone binding globulin (SHBG) was performed on Immulite 2000 (Diagnostic Product Corp., Los Angeles, CA, USA). The intra- and interassay coefficients of variation (CV) for total testosterone were 3.5\% and 5\% respectively at a concentration above $1 \mathrm{nmol} / \mathrm{l}$ and $12 \%$ and $20 \%$ respectively in the range 0.1 (limit of detection) to $1.0 \mathrm{nmol} / \mathrm{l}$. For SHBG the intra- and interassay CVs were $3.5 \%$ and $6 \%$ respectively and limit of detection was $1.0 \mathrm{nmol} / \mathrm{l}$. Eight men $(0.5 \%)$ had total testosterone values below the detection level, and for this analysis, their levels were converted to values midway between zero and assay sensitivity level. Seven men (0.4\%) had SHBG levels $>180 \mathrm{nmol} / \mathrm{l}$, and their levels were converted to $180 \mathrm{nmol} / \mathrm{l}$.

Free testosterone values were calculated from total testosterone and SHBG according to Vermeulen et al. and Södergård et al. $(15,16)$ :

$$
\mathrm{FT}=([T]-(N \times[\mathrm{FT}])) /\left(K_{\mathrm{t}}\{\mathrm{SHBG}-[\mathrm{T}]+N[\mathrm{FT}]\}\right)
$$

where FT is the concentration of free testosterone; $T$ is the concentration of total testosterone; $N=K_{\mathrm{a}} C_{\mathrm{a}}+1$ (where $K_{\mathrm{a}}$ is the association constant of albumin for testosterone $=3.6 \times 10^{4} \mathrm{l} / \mathrm{mol}$ and $C_{\mathrm{a}}$ is the albumin concentration set to $\left.6.2 \times 10^{-4} \mathrm{~mol} / \mathrm{l}\right) ; K_{\mathrm{t}}$ is the association constant of SHBG for testosterone $=1 \times 10^{9}$ $\mathrm{l} / \mathrm{mol}$; and SHBG is the concentration of sex hormone-binding globulin.

This yields a second-degree equation, and solving this for free testosterone gives the following solution:

$$
\begin{aligned}
\mathrm{FT}= & \left(-\left(\left(K_{\mathrm{t}} \times \mathrm{SHBG}\right)-\left(K_{\mathrm{t}} \times T\right)+N\right) \pm \sqrt{ }\left(\left(\left(K_{\mathrm{t}} \times \mathrm{SHBG}\right)\right.\right.\right. \\
& \left.\left.-\left(K_{\mathrm{t}} \times T\right)+N\right)^{2}+\left(4 \times\left(K_{\mathrm{t}} \times N\right) \times(-T)\right)\right) / \\
& \left(2 \times\left(K_{\mathrm{t}} \times N\right)\right)
\end{aligned}
$$

Root expression is: $\sqrt{ }\left(\left(\left(K_{\mathrm{t}} \times \mathrm{SHBG}\right)-\left(K_{\mathrm{t}} \times T\right)+N\right)^{2}\right.$ $\left.+\left(4 \times\left(K_{\mathrm{t}} \times N\right) \times(-T)\right)\right)$.

\section{Statistical analyses}

Multiple linear regression models were used to determine the contribution of age, BMI, smoking, coffee and alcohol consumption, and physical activity to hormone levels. Analysis of covariance was used to calculate adjusted means of sex hormones and SHBG by lifestyle factors and chronic disease; age and BMI were used as continuous variables and as covariates in the model. The independent relationship between age, BMI and lifestyle factors and hormone levels was tested with logistic regression analysis, where hormone levels were treated as the dependent variable. The model calculates the odds ratio (OR) for being in the lowest quintile of the dependent variable. All statistical tests were two-tailed with statistical significance defined as $P<0.05$. The data were analyzed using the SPSS statistical package for Windows version 10.1 (SPSS Inc., Chicago, IL, USA).

\section{Ethics}

The Tromsø Regional Ethics Committee approved the study, and all participants gave written informed consent.

\section{Results}

Characteristics of the 1563 men are shown in Table 1, and in Table 2 the distribution and variation of mean 
total and free testosterone, SHBG, BMI and lifestyle factors by age (in decades) are presented.

Table 3 shows an inverse linear association between age and both total testosterone $(P=0.001)$ and free testosterone $(P<0.001)$. The decline of total testosterone with age was consistent but, as shown in Fig. 1, the variation was wide. Figure 1 also shows a consistent and more pronounced decrease of free testosterone with age. Table 3 also shows an inverse association between BMI and total testosterone $(P<0.001)$ and free testosterone $(P=0.016)$. Both total and free testosterone were positively and significantly associated with tobacco consumption $(P<0.001$ and $P=0.004)$

Table 1 Characteristics of the 1563 Troms $ø$ men.

\begin{tabular}{lc}
\hline & Mean \pm s.D. \\
\hline Age (years) & $60 \pm 10$ \\
Anthropometric characteristics & $175 \pm 7$ \\
$\quad$ Height $(\mathrm{cm})$ & $80.0 \pm 12.2$ \\
Weight $(\mathrm{kg})$ & $26.0 \pm 3.4$ \\
BMI (kg/m $\left.{ }^{2}\right)$ & \\
Hormone levels & $13.2 \pm 5.2$ \\
Total testosterone (nmol/l) & $204 \pm 77$ \\
Free testosterone (pmol/l) & $52.4 \pm 24.0$ \\
SHBG (nmol/l) & $\%$ \\
Lifestyle factors & 33 \\
Smoking - yes (\%) & 63 \\
Coffee - >4 cups/day (\%) & 25 \\
Alcohol - >6 drinks/2 weeks (\%) & 29 \\
Physical activity (vigorous) - $\geq 3 \mathrm{~h} /$ week (\%) & \\
\hline
\end{tabular}

and total but not free testosterone was positively and significantly associated with coffee consumption $(P<0.001)$. No associations between total or free testosterone with physical activity or alcohol consumption were found.

SHBG was positively associated with age $(P<0.001)$. An inverse association between SHBG and BMI $(P<0.001)$ was also found. SHBG was positively associated with smoking $(P=0.004)$ and coffee consumption $(P<0.001)$, but there was no association between SHBG and alcohol consumption or weekly exercise.

Table 4 shows that smokers have significantly higher levels of total testosterone ( 14.4 vs $12.5 \mathrm{nmol} / \mathrm{l} ; \mathrm{P}<$ $0.001)$, free testosterone $(214$ vs $199 \mathrm{pmol} / \mathrm{l}$; $P<0.001)$ and SHBG $(56.3$ vs $50.0 \mathrm{nmol} / \mathrm{l} ; \quad P<$ 0.001 ), adjusted for age and BMI. Men with a high coffee consumption also have increased levels of total testosterone (13.7 vs $12.3 \mathrm{nmol} / \mathrm{l} ; \quad P<0.001)$, free testosterone (206 vs $199 \mathrm{pmol} / \mathrm{l} ; P<0.05)$ and SHBG ( 54.2 vs $49.2 \mathrm{nmol} / \mathrm{l} ; P<0.001$ ). No difference in hormone levels was found between men reporting moderate to high alcohol consumption and men reporting low alcohol consumption or among men reporting different levels of weekly physical activity.

Table 5 shows that men who reported having had a stroke or a cancer diagnosis had significantly lower levels of total testosterone $(10.2$ vs $13.2 \mathrm{nmol} / \mathrm{l}$; $P<0.001$ and 11.1 vs $13.2 \mathrm{nmol} / \mathrm{l} ; P<0.01$ respectively) and free testosterone (174 vs $205 \mathrm{pmol} / \mathrm{l}$;

Table 2 The distribution of total and free testosterone, and SHBG levels, BMI and lifestyle factors in relation to age groups.

\begin{tabular}{|c|c|c|c|c|c|c|c|c|c|}
\hline Age & $n$ & $\begin{array}{l}\text { Total testosterone } \\
\qquad(\mathrm{nmol} / \mathrm{l})\end{array}$ & $\begin{array}{l}\text { Free testosterone } \\
\qquad(\mathrm{pmol} / \mathrm{l})\end{array}$ & $\begin{array}{l}\text { SHBG } \\
(\mathrm{nmol} / \mathrm{l})\end{array}$ & $\begin{array}{c}\text { BMI } \\
\left(\mathrm{kg} / \mathrm{cm}^{2}\right)\end{array}$ & $\begin{array}{c}\text { Smoking } \\
(\%)\end{array}$ & $\begin{array}{c}\text { Coffee } \\
(\%)\end{array}$ & $\begin{array}{c}\text { Alcohol } \\
(\%)\end{array}$ & $\begin{array}{c}\text { Physical activity } \\
(\%)\end{array}$ \\
\hline $25-39$ & 75 & $14.7(6.0)$ & 295 (108) & $36.0(15.1)$ & $24.6(2.9)$ & 37 & 72 & 34 & 48 \\
\hline $40-49$ & 124 & $13.8(5.0)$ & 254 (79) & $39.6(16.6)$ & $27.1(3.3)$ & 45 & 74 & 35 & 43 \\
\hline $50-59$ & 454 & $13.3(5.1)$ & $218(75)$ & 47.3 (20.3) & $26.6(3.1)$ & 38 & 72 & 30 & 31 \\
\hline $60-69$ & 614 & $13.1(5.2)$ & $190(62)$ & 55.7 (24.7) & 26.1 (3.5) & 35 & 67 & 23 & 25 \\
\hline $70-84$ & 296 & $12.5(5.3)$ & $168(62)$ & $62.0(25.7)$ & $25.5(3.8)$ & 26 & 54 & 13 & 22 \\
\hline$P$-trend & & $P<0.001$ & $P<0.001$ & $P<0.001$ & $P=0.394$ & $P<0.001$ & $P<0.001$ & $P<0.001$ & $P<0.001$ \\
\hline
\end{tabular}

Smoking (yes); coffee ( $>4$ cups/day); alcohol ( $>6$ drinks/2 weeks); physical activity, vigorous ( $\geq 3 \mathrm{~h} /$ week).

Table 3 Multiple linear regression models with total and free testosterone and SHBG as dependent variables.

\begin{tabular}{|c|c|c|c|c|c|c|}
\hline \multirow[b]{3}{*}{ Independent variables } & \multicolumn{6}{|c|}{ Dependent variables } \\
\hline & \multicolumn{2}{|c|}{ Total testosterone } & \multicolumn{2}{|c|}{ Free testosterone } & \multicolumn{2}{|c|}{ SHBG } \\
\hline & $\beta \dagger$ & $P$ & $\beta \dagger$ & $P$ & $\beta \dagger$ & $P$ \\
\hline Age & -0.08 & 0.001 & -0.41 & $<0.001$ & 0.32 & $<0.001$ \\
\hline BMI & -0.30 & $<0.001$ & -0.06 & 0.016 & -0.38 & $<0.001$ \\
\hline Smoking - cigarettes/day & 0.11 & $<0.001$ & 0.07 & 0.004 & 0.07 & 0.004 \\
\hline Coffee - cups/day & 0.11 & 0.018 & 0.02 & NS & 0.10 & $<0.001$ \\
\hline Alcohol - drinks/2 weeks & -0.02 & NS & 0.02 & NS & -0.05 & NS \\
\hline Physical activity score & -0.01 & NS & -0.01 & NS & 0.03 & NS \\
\hline Adjusted $R^{2}$ & \multicolumn{2}{|c|}{0.135} & \multicolumn{2}{|c|}{0.185} & \multicolumn{2}{|c|}{0.276} \\
\hline
\end{tabular}

†Standardized beta coefficient. 

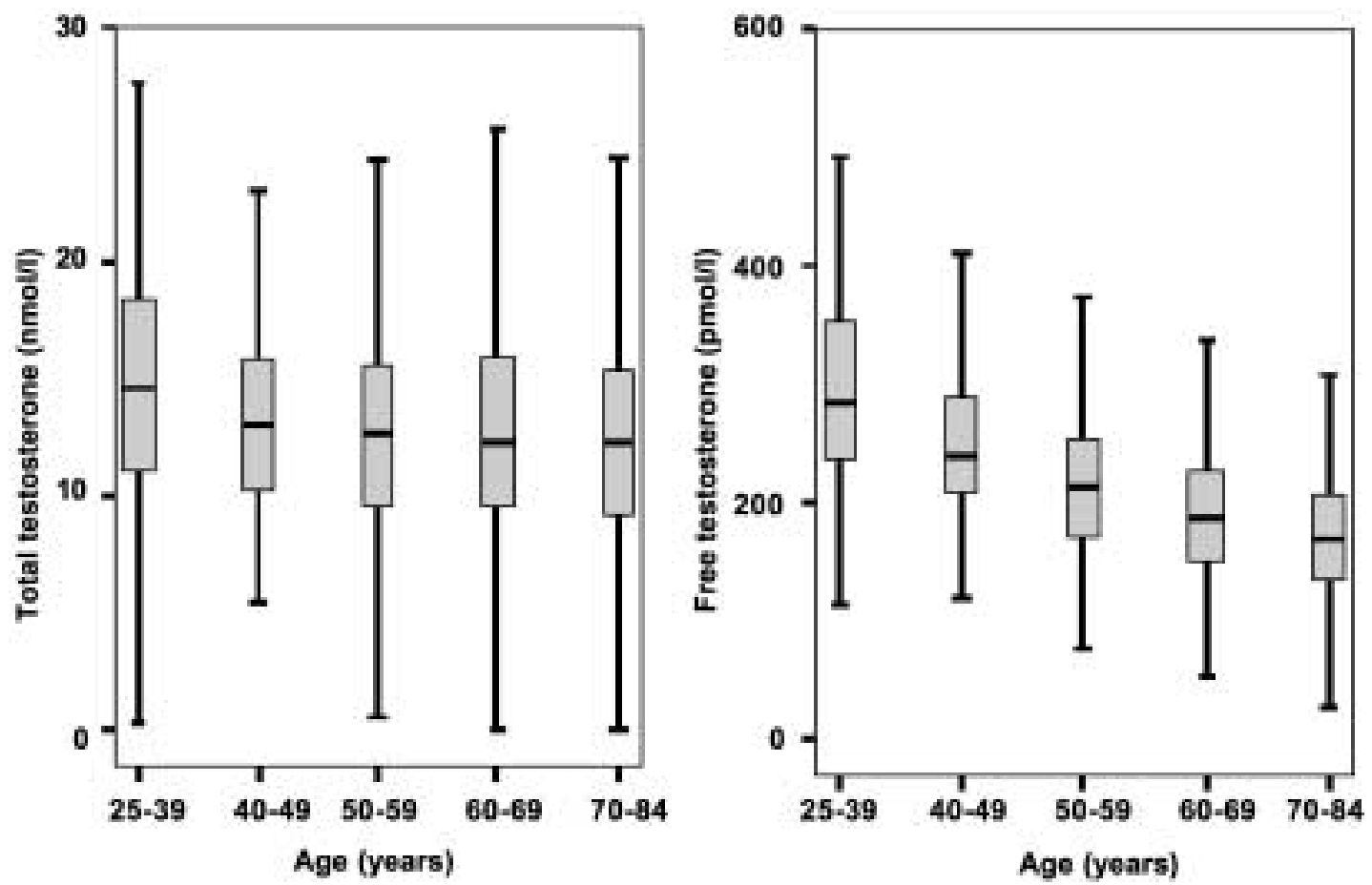

Figure 1 Box plot of total and free testosterone (median, 25th, 75th percentiles and whiskers) by age groups.

$P<0.01$ and 175 vs $205 \mathrm{pmol} / \mathrm{l} ; P<0.01$ respectively), after adjusting for age and BMI. SHBG levels were significantly lower in men reporting stroke $(45.3$ vs $52.4 \mathrm{nmol} / \mathrm{l} ; \quad P<0.05)$. Men with ischemic heart disease (IHD) had significantly higher levels of free testosterone $(215$ vs $202 \mathrm{pmol} / \mathrm{l}$; $P<0.01)$. After adjusting for age and BMI, no significant difference in hormone levels was found in men with diabetes compared with men without diabetes, and there was no difference between having a chronic disease and not.

Table 6 shows that men with a high BMI $\left(>25 \mathrm{~kg} / \mathrm{cm}^{2}\right)$ were more likely $(\mathrm{OR}=1.984 ; \mathrm{P}<$
$0.001)$ and smokers less likely $(\mathrm{OR}=0.495 ; \mathrm{P}<$ $0.001)$ to be in the lowest quintile of total testosterone $(\leq 9.0 \mathrm{nmol} / \mathrm{l})$, while there was no relationship with age, coffee and alcohol consumption, and physical activity. Older men were more likely $(\mathrm{OR}=$ 1.078/year; $P<0.001)$ and smokers less likely (OR $0.687 ; P=0.017)$ to be in the lowest quintile of free testosterone.

There was a negative correlation between the time of day of venipuncture and both total and free testosterone. Adjusting for sample time did not change any of the results, and a stratified analysis with samples drawn before and after $1100 \mathrm{~h}$ did not materially

Table 4 Age- and BMI-adjusted mean levels of total and free testosterone and SHBG in relation to lifestyle factors.

\begin{tabular}{|c|c|c|c|}
\hline & $\begin{array}{l}\text { Total testosterone } \\
\qquad(\mathrm{nmol} / \mathrm{l})\end{array}$ & $\begin{array}{l}\text { Free testosterone } \\
\qquad(\mathrm{pmol} / \mathrm{l})\end{array}$ & $\begin{array}{l}\text { SHBG } \\
(\mathrm{nmol} / \mathrm{l})\end{array}$ \\
\hline \multicolumn{4}{|l|}{ Smoking } \\
\hline Yes & $14.4 \ddagger$ & $214 \ddagger$ & $56.3 \ddagger$ \\
\hline No & 12.5 & 199 & 50.0 \\
\hline \multicolumn{4}{|l|}{ Coffee } \\
\hline$>4$ cups/day & $13.7 \ddagger$ & $206^{*}$ & $54.2 \ddagger$ \\
\hline $1-4$ cups/day & 12.3 & 199 & 49.2 \\
\hline \multicolumn{4}{|l|}{ Alcohol } \\
\hline$>6$ drinks/2 weeks & 13.2 & 205 & 51.9 \\
\hline$\leq 6$ drinks/2 weeks & 13.0 & 195 & 54.4 \\
\hline \multicolumn{4}{|c|}{ Physical activity (vigorous) } \\
\hline$<3 \mathrm{~h} /$ week & 13.2 & 205 & 52.8 \\
\hline$\geq 3 \mathrm{~h} /$ week & 13.1 & 202 & 51.8 \\
\hline
\end{tabular}

${ }^{*} P<0.05 ; \ddagger P<0.001$. 
Table 5 Age-adjusted and age- and BMI-adjusted mean levels of total and free testosterone and SHBG in relation to a variety of chronic diseases.

\begin{tabular}{|c|c|c|c|c|c|c|c|c|c|c|}
\hline \multirow[b]{2}{*}{$n$} & \multicolumn{2}{|c|}{ Diabetes } & \multicolumn{2}{|c|}{ IHD } & \multicolumn{2}{|c|}{ Stroke } & \multicolumn{2}{|c|}{ Cancer } & \multicolumn{2}{|c|}{$\begin{array}{l}\text { Chronic } \\
\text { disease }\end{array}$} \\
\hline & $\begin{array}{c}\text { No } \\
1513\end{array}$ & $\begin{array}{l}\text { Yes } \\
50\end{array}$ & $\begin{array}{c}\text { No } \\
1326\end{array}$ & $\begin{array}{l}\text { Yes } \\
237\end{array}$ & $\begin{array}{c}\text { No } \\
1521\end{array}$ & $\begin{array}{l}\text { Yes } \\
42\end{array}$ & $\begin{array}{l}\text { No } \\
1508\end{array}$ & $\begin{array}{l}\text { Yes } \\
55\end{array}$ & $\begin{array}{c}\text { No } \\
1224\end{array}$ & $\begin{array}{l}\text { Yes } \\
339\end{array}$ \\
\hline \multicolumn{11}{|l|}{ Total testosterone $(\mathrm{nmol} / \mathrm{l})$} \\
\hline Age-adjusted & 13.2 & $11.2 \dagger$ & 13.2 & 13.1 & 13.2 & $9.9 \ddagger$ & 13.2 & $11.5^{\star}$ & 13.4 & $12.4 \dagger$ \\
\hline \multicolumn{11}{|l|}{ Free testosterone $(\mathrm{pmol} / \mathrm{l})$} \\
\hline Age-adjusted & 204 & 201 & 202 & $214^{*}$ & 205 & $173+$ & 205 & $176+$ & 204 & 203 \\
\hline $\begin{array}{l}\text { Age- and BMl-adjusted } \\
\text { SHBG (nmol/l) }\end{array}$ & 204 & 203 & 202 & $215 \dagger$ & 205 & $174 \dagger$ & 205 & $175 \dagger$ & 204 & 204 \\
\hline Age-adjusted & 52.6 & $40.6 \ddagger$ & 53.1 & $47.7 \dagger$ & 52.5 & $43.7^{*}$ & 52.0 & $58.8^{*}$ & 53.1 & $49.1 \dagger$ \\
\hline Age- and BMI-adjusted & 52.4 & $46.4^{\star}$ & 52.6 & 50.0 & 52.4 & $45.3^{*}$ & 52.0 & 56.9 & 52.6 & 50.8 \\
\hline
\end{tabular}

$\mathrm{IHD}=$ ischemic heart disease (angina and/or myocardial infarction); chronic disease = a combination of the diseases in the table (some individuals had more than one disease).

${ }^{\star} P<0.05 ; \dagger P<0.01 ; \ddagger P<0.001$.

Table 6 Logistic regression models with the lowest quintile vs all other values for total and free testosterone.

\begin{tabular}{|c|c|c|c|}
\hline & OR & $95 \% \mathrm{Cl}$ & $\boldsymbol{P}$ \\
\hline \multicolumn{4}{|l|}{ Total testosterone } \\
\hline Age & 1.014 & $0.999-1.029$ & NS \\
\hline $\mathrm{BMI}-\leq 25 \mathrm{vs}>25 \mathrm{~kg} / \mathrm{cm}^{2}$ & 1.984 & $1.470-2.677$ & $<0.001$ \\
\hline Smoking - no vs yes & 0.495 & $0.362-0.679$ & $<0.001$ \\
\hline Coffee $-1-4$ cups vs $>4$ cups/day & 0.888 & $0.672-1.175$ & NS \\
\hline Alcohol $-\leq 6$ drinks vs $>6$ drinks $/ 2$ weeks & 1.300 & $0.962-1.758$ & NS \\
\hline Physical activity (vigorous) $-\geq 3 \mathrm{~h}$ vs $<3 \mathrm{~h} /$ week & 1.097 & $0.813-1.480$ & NS \\
\hline \multicolumn{4}{|l|}{ Free testosterone } \\
\hline Age & 1.078 & $1.058-1.097$ & $<0.001$ \\
\hline $\mathrm{BMI}-\leq 25 \mathrm{vs}>25 \mathrm{~kg} / \mathrm{cm}^{2}$ & 0.962 & $0.728-1.271$ & NS \\
\hline Smoking - no vs yes & 0.687 & $0.507-0.931$ & 0.017 \\
\hline Coffee $-1-4$ cups vs $>4$ cups/day & 0.960 & $0.723-1.275$ & NS \\
\hline Alcohol $-\leq 6$ drinks vs $>6$ drinks $/ 2$ weeks & 1.064 & $0.772-1.467$ & NS \\
\hline Physical activity (vigorous) $-\geq 3 \mathrm{~h}$ vs $<3 \mathrm{~h} /$ week & 1.130 & $0.829-1.539$ & NS \\
\hline
\end{tabular}

$\mathrm{Cl}=$ confidence interval.

change the result (data not shown). A seasonal variation was found for total and free testosterone and SHBG (data not shown).

All analyses were performed on individuals with or without chronic diseases, but as this did not change the observed variations of sex hormones, only analyses of the total population are shown.

\section{Discussion}

\section{Variations with age}

In this large cohort of men from a general population we found an age-related decrease of total and free testosterone in men, consistent with the result from the Massachusetts Male Aging Study (MMAS) $(2,5)$ and the Baltimore Longitudinal Study of Aging (4), and in disagreement with the Rancho Bernardo Study (3). However, in the Rancho Bernardo men, an age-associated decline in testosterone was seen after adjusting for covariates. The decline in testosterone production is suggested to be a normal part of aging, with reduced testicular activity as well as a down-regulation of the hypothalamic-pituitary feedback system $(17,18)$. Because of the age-related increase of SHBG in our Tromsø men, consistent with recent studies $(2,4,5)$, the age-related reduction of free testosterone was more prominent compared with total testosterone.

Sex steroids circulate in serum bound to SHBG and albumin and as free steroids. Most investigators believe that the free and the albumin-bound fractions, the non-SHBG bound fraction, of circulating hormones are biologically active. The serum concentration of SHBG would therefore be a main factor influencing the biologically active fractions, as there are only small variations in albumin concentrations in healthy subjects. Thus, in older men total testosterone is maintained at relatively high levels, compared with free testosterone. 


\section{Variations with lifestyle factors}

Smoking was positively and significantly associated with total and free testosterone and SHBG in Tromsø men, also after adjustment for age, BMI, and other covariates. However, the effects of cigarette smoking on testosterone levels in men generally conflict. Total testosterone has been found to be lower (19), similar (10) or higher $(4,20-23)$ in healthy male smokers than in non-smokers. Three studies have reported an increase of free testosterone in smokers $(20,21,23)$. Bioavailable testosterone and SHBG levels have only been measured in two of these studies $(22,23)$; SHBG was higher in smokers than non-smokers, but no difference in bioavailable testosterone was observed. Thus, English et al. (23) suggested that the increase in total testosterone levels was secondary to the raised SHBG levels; furthermore, SHBG levels but not testosterone levels were found to correlate with cotinine levels (a measure of cigarette smoking), indicating that smoking has a greater relative effect on SHBG levels. However, adjusting for SHBG in our study did not change the association between testosterone and smoking, and nor did adjusting for free testosterone change the association between SHBG and smoking (data not shown). The relationship between levels of total and free testosterone, SHBG, and smoking is still elusive and needs further investigations, perhaps in a more experimental setting.

Coffee consumption was positively associated with total testosterone, with or without adjustments for covariates, and to our knowledge this association has not previously been described. SHBG levels were positively associated with coffee consumption, probably explaining the lack of association with free testosterone. Caffeine intake was positively correlated with bioavailable testosterone in a previous study, but no adjustments for age or BMI were made (3). As SHBG is produced in the liver, the results suggest a caffeine effect on hepatic metabolism.

No association was found between total or free testosterone levels and alcohol consumption or physical activity or between SHBG and alcohol consumption or physical activity. Alcohol consumption and physical activity are not precisely estimated from self-report, however, and misclassification could have obscured these associations.

\section{Variation with chronic disease}

Total and free testosterone concentrations were lower in men reporting having had a stroke compared with men who had not. Our findings are supported by a recent study finding lower levels of both total and free testosterone in men suffering acute ischemic stroke. However, a slight but not significant increase of hormone levels was noted at the 6-month followup, possibly suggesting in part an acute effect on the hypothalamic-pituitary-testicular axis (8). We also found lower levels of total and free testosterone in men with cancer, and a higher level of free testosterone in men with IHD. Thus some diseases seem to have an effect on testosterone levels, but it must also be taken into account that being diagnosed with a disease might lead to changes in lifestyle and risk factors.

\section{Variation with anthropometry}

In healthy men, body weight and total fat content have been observed to increase with advancing age while free testosterone levels decrease (13). In our study, BMI was not associated with age, while both total and free testosterone levels decreased with increasing BMI. Increased BMI and waist-hip ratio (WHR) are seen in hypogonadal men $(24,25)$ and reduced total testosterone levels have been found in obese young men (26-28). Furthermore, low-dose testosterone administered to hypogonadal men has been found to have a positive effect on body composition with increasing muscle mass and decreasing fat mass regardless of cause of hypogonadism (29-32), suggesting a dual relationship between body composition and total and free testosterone levels. In our analysis BMI was the most important predictor of total testosterone variation, and to a lesser degree a predictor of free testosterone.

Low levels of SHBG have been associated with obesity (26), and weight loss in obese men has normalized SHBG levels (33). It has been suggested that SHBG levels probably are related to general metabolic factors. We found a significant and inverse association between SHBG and BMI, and in our study BMI was the strongest predictor of the SHBG variation, as well.

\section{Limitations}

Hormone levels were based on a single serum sample, drawn between 0800 and $1600 \mathrm{~h}$. Preferably, samples should have been drawn in the morning because of the diurnal variation of total and free testosterone, and sample time was associated with both total and free testosterone, with expected higher levels of testosterone in the morning. However, stratified analysis for sample time did not change any associations or lack of associations. Our samples were kept frozen for approximately 6.5 years at $-70^{\circ} \mathrm{C}$, and hormone levels were measured when samples were thawed for the first time. Levels of steroid hormones have been shown to be relatively stable in frozen serum for up to 10 years $(34,35)$. SHBG has been shown to be stable in short-term frozen storage (35), but reduced levels have been reported after longer storage (4). However, this would not be expected to alter the ordinal associations for observed levels. We did not measure free testosterone but used calculated values. However, this calculation was recently evaluated by two different investigators, and found to be a reliable index of free 
testosterone $(15,36)$. Furthermore, it should be recognized that the results of this study are obtained from cross-sectional data and do not provide direct evidence of cause and effect.

In summary, our study confirms an age-related decline of both total and free testosterone, paralleling an age-related increase in SHBG. BMI and smoking are independent contributors to the variation of total and free testosterone and SHBG levels, and coffee consumption to the variation of total testosterone and SHBG. Thus, lifestyle factors can have a direct effect on circulating levels of free endogenous sex hormones and to total levels due to the effect on SHBG levels, indicating that the effect of lifestyle factors on sex hormones needs to be considered in clinical practice. However, the impact of age and BMI on the variation of sex hormones is much more powerful. Furthermore, in clinical practice today total testosterone is mainly used for evaluation of potential hypogonadism, but our data suggest that free testosterone levels could be a complementary tool in diagnosing hypogonadism.

\section{Acknowledgements}

While preparing this manuscript one of the authors, Monica Midtby, died after a long period of illness. We are deeply grateful for her contribution to this manuscript. This study was supported with a grant from The Norwegian Endocrine Society (provided by Bayer Corp., Norway) and local funding at the University Hospital of North Norway. The excellent technical assistance of Astrid Lindvall and Inger Myrnes, Department of Clinical Chemistry, with the sex hormone analyses is greatly appreciated.

\section{References}

1 Gray A, Berlin JA, McKinlay JB \& Longcope C. An examination of research design effects on the association of testosterone and male aging: results of a meta-analysis. Journal of Clinical Epidemiology $199144671-684$.

2 Gray A, Feldman A, McKinlay JB \& Longcope C. Age, disease, and changing sex hormone levels in middle-aged men: result of the Massachusetts Male Aging Study. Journal of Clinical Endocrinology and Metabolism 199173 1016-1025.

3 Ferrini RL \& Barrett-Connor E. Sex hormones and age: a crosssectional study of testosterone and estradiol and their bioavailable fractions in community-dwelling men. American Journal of Epidemiology 1998147 750-754.

4 Harman SM, Metter EJ, Tobin JD, Pearson J \& Blackman MR. Longitudinal effects of aging on serum total and free testosterone levels in healthy men. Journal of Clinical Endocrinology and Metabolism $2001 \mathbf{8 6} 724-731$.

5 Feldman HA, Longcope C, Derby CA, Johannes CB, Araujo AB, Coviello $\mathrm{AD}$ et al. Age trends in the level of serum testosterone and other hormones in middle-aged men: Longitudinal results from the Massachusetts Male Aging Study. Journal of Clinical Endocrinology and Metabolism 200287 589-598.

6 Phillips GB, Jing T-Y, Resnick LM, Barbagallo M, Laragh JH \& Sealey JE. Sex hormones and hemostatic risk factors for coronary heart disease in men with hypertension. Journal of Hypertension $199311699-702$

7 Goodman-Gruen D \& Barrett-Connor E. Sex differences in the association of endogenous sex hormone levels and glucose tolerance status in older men and women. Diabetes Care 200023 912-918.

8 Jeppesen LL, Jørgensen HS, Nakayama H, Raaschou HO, Skyhøj T \& Winther K. Decreased serum testosterone in men with acute ischemic stroke. Arteriosclerosis, Thrombosis, and Vascular Biology $199616749-754$.

9 Henderson BE, Ross RK, Pike MC \& Casagrande JT. Endogenous hormones as a major factor in human cancer. Cancer Research $1982423232-3239$.

10 Barrett-Connor E \& Khaw K-T. Cigarette smoking and increased endogenous estrogen levels in men. American Journal of Epidemiology 1987126 187-192.

11 Kujala UM, Alen M \& Huhtaniemi IT. Gonadotrophin-releasing hormone and human chorionic gonadotropin tests reveal that both hypothalamic and testicular endocrine functions are suppressed during acute prolonged physical exercise. Clinical Endocrinology 199033 219-225.

12 Zmuda JM, Cauley JA, Kriska A, Glynn NW, Gutai JP \& Kuller LH. Longitudinal relation between endogenous testosterone and cardiovascular disease risk factors in middle-age men. A 13-year follow-up of former Multiple Risk Factor Intervention Trial participants. American Journal of Epidemiology 1997146 609-617.

13 Vermeulen A, Goemaere S \& Kaufman JM. Testosterone, body composition and aging. Journal of Endocrinological Investigation 199922 110-116.

14 Thelle DS, Førde OH, Try K \& Lehmann EH. The Tromsø heart study. Methods and main results of the cross-sectional study. Acta Medica Scandinavica $1976200107-118$.

15 Vermeulen A, Verdonck L \& Kaufman JM. A critical evaluation of simple methods for the estimation of free testosterone in serum. Journal of Clinical Endocrinology and Metabolism $1999 \quad \mathbf{8 4}$ 3666-3672.

16 Södergård R, Bäckström T, Shanbhag V \& Carstensen H. Calculation of free and bound fractions of testosterone and estradiol17 beta to human plasma proteins at body temperature. Journal of Steroid Biochemistry $198216801-810$.

17 Winters SJ \& Troen P. Episodic luteinizing hormone (LH) secretion and the response of $\mathrm{LH}$ and follicle-stimulating hormone to LHreleasing hormone in aged men: evidence for coexistent primary testicular insufficiency and an impairment in gonadotropin secretion. Journal of Clinical Endocrinology and Metabolism 1982 $55560-565$.

18 Deslypere JP, Kaufman JM, Vermeulen T, Vogelaers D, Vandalem JL \& Vermeulen A. Influence of age on pulsatile luteinizing hormone release and responsiveness of the gonadotrophs to sex hormone feedback in men. Journal of Clinical Endocrinology and Metabolism $19876468-73$.

19 Shaarawy M \& Mahmoud KZ. Endocrine profile and semen characteristics in male smokers. Fertility and Sterility $1982 \mathbf{3 8}$ 255-257.

20 Handa K, Ishii H, Kono S, Shinchi K, Imanishi K, Mihara H et al. Behavioral correlates of plasma sex hormones and their relationships with plasma lipids and lipoproteins in Japanese men. Atherosclerosis $199713037-44$.

21 Dai WS, Gutai JP, Kuller LH \& Cauley JA. Cigarette smoking and serum sex hormones in men. American Journal of Epidemiology $1988128796-805$.

22 Field AE, Colditz GA, Willett WC, Longcope C \& McKinlay JB. The relation of smoking, age, relative weight and dietary intake to serum adrenal steroids, sex hormones, and sex hormone-binding globulin in middle-aged men. Journal of Clinical Endocrinology and Metabolism 199479 1310-1316.

23 English KM, Pugh PJ, Parry H, Scutt NE, Channer KS \& Jones TH. Effect of cigarette smoking on levels of bioavailable testosterone in healthy men. Clinical Science 2001100 661-665. 
24 Katznelson L, Finkelstein IS, Schoenfeld DA, Rosenthal DI, Anderson EJ \& Klibanski A. Increase in bone density and lean body mass during testosterone administration in men with acquired hypogonadism. Journal of Clinical Endocrinology and Metabolism $1996 \mathbf{8 1} 4358-4365$.

25 Mårin P \& Arver S. Androgens and abdominal obesity. Baillière's Clinical Endocrinology and Metabolism 199812 441-451.

26 Glass AR, Swerdloff RS, Bray GA, Dahms WT \& Atkinson RL. Low serum testosterone and sex-hormone-binding-globulin in massively obese men. Journal of Clinical Endocrinology and Metabolism 197745 1211-1219.

27 Zumoff B, Strain GW, Miller LK, Rosner W, Senie R, Seres DS et al. Plasma free and non-sex-hormone-binding-globulin-bound testosterone are decreased in obese men in proportion to their degree of obesity. Journal of Clinical Endocrinology and Metabolism 199071 929-931.

28 Vermeulen A, Kaufman JM, Deslypere JP \& Thomas G. Attenuated luteinizing hormone (LH) pulse amplitude but normal LH pulse frequency, and its relation to plasma androgens in hypogonadism and obese men. Journal of Clinical Endocrinology and Metabolism 199376 1140-1146.

29 Rebuffe-Scrive M, Mårin P \& Björntorp P. Effect of testosterone on abdominal adipose tissue in men. International Journal of Obesity $199115791-795$.

30 Bhasin S, Storer TW, Berman N, Yarasheski KE, Clevenger B, Phillips $\mathrm{J}$ et al. Testosterone replacement increases fat-free mass and muscle size in hypogonadal men. Journal of Clinical Endocrinology and Metabolism 199782 407-413.
31 Snyder PJ, Peachey H, Hannoush P, Berlin JA, Loh L, Lenrow DA et al. Effect of testosterone treatment on body composition and muscle strength in men over 65 years of age. Journal of Clinical Endocrinology and Metabolism 199984 2647-2653.

32 Snyder PJ, Peachey H, Berlin JA, Hannoush P, Haddad G, Dlewati A et al. Effects of testosterone replacement in hypogonadal men. Journal of Clinical Endocrinology and Metabolism $2000 \mathbf{8 5}$ $2670-2677$.

33 Pasquali R, Vicennati V, Scopinaro N, Marinari G, Simonelli A, Flamia $\mathrm{R}$ et al. Achievement of near-normal body weight as the prerequisite to normalize sex hormone-binding globulin concentrations in massively obese men. International Journal of Obesity 199721 1-5.

34 Bolelli G, Muti P, Micheli A, Sciajno R, Franceschetti F, Krogh V et al. Validity for epidemiological studies of long-term cryoconservation of steroid and protein hormones in serum and plasma. Cancer Epidemiology, Biomarkers and Prevention 19954 509-513.

35 Kley HK, Schlaghecke R \& Kruskemper HL. Stability of steroid in plasma over a 10-year period. Journal of Clinical Chemistry and Clinical Biochemistry 198523 875-878.

36 Morley JE, Patrick P \& Perry HM 3rd. Evaluation of assays available to measure free testosterone. Metabolism $200251554-559$.

Received 18 February 2003

Accepted 13 May 2003 